\title{
PENGEMBANGAN TRAINER INDIKATOR DENYUT JANTUNG
}

\author{
Pipit Utami ${ }^{1}$, Muklas Fajar ${ }^{2}$ \\ Universitas Negeri Yogyakarta $^{1}$, SELTech $^{2}$ \\ e-mail: pipitutami@uny.ac.id
}

\begin{abstract}
ABSTRAK
Salah satu capaian pembelajaran mata kuliah instrumentasi adalah mampu menjelaskan penggunaan konsep instrumentasi pada penerapan teknologi instrumentasi. Pengembangan media merupakan salah satu upaya mencapai capaian pembelajaran tersebut. Penerapan teknologi instrumentasi yang diangkat dalam penelitian ini adalah penggunaan photodioda sebagai sensor denyut jantung yang memungkinkan penggunaan berbagai macam rangkaian pengkondisi sinyal untuk memodifikasi sinyal ke output. Artikel ini bertujuan untuk mendeskripsikan desain media berdasarkan analisis kebutuhan dan memaparkan hasil evaluasi pengembangan media tersebut. Media dikembangkan dengan tahapan analisis kebutuhan, desain, pengembangan dan evaluasi. Hasil menunjukkan bahwa: (1) media berupa trainer berbentuk kotak yang berisikan titik-titik pengukuran (sensor, pengkondisi sinyal dan output) diatas skema rangkaian sesungguhnya dan jobsheet praktik; dan (2) evaluasi menunjukkan bahwa trainer memiliki unjuk kerja yang sesuai dan mendapat penilaian layak dari mahasiswa. Sebagai tambahan penggunaan trainer tersebut memudahkan mahasiswa dalam memaparkan variabel proses, sensor, pengkondisi sinyal dan output dari media pembelajaran pengukur denyut jantung yang dikembangkan.
\end{abstract}

Kata kunci: pengembangan, pengkondisi sinyal, photodioda, instrumentasi

\section{PENDAHULUAN}

Dalam pasal 29 Undang-undang Republik Indonesia nomor 12 tahun 2012 tentang Pendidikan Tinggi menyatakan bahwa Kerangka Kualifikasi Nasional (KKNI) menjadi acuan pokok dalam penetapan kompetensi lulusan pendidikan akademik (Republik, 2012). Dari sembilan jenjang kualifikasi pada KKNI, lulusan S1 Program Studi Pendidikan Teknik Elektronika (Prodi PTE) berada pada level 6. Secara umum, kompetensi lulusan S1 dari deskripsi level 6 KKNI diantaranya adalah mampu mengaplikasikan bidang keahlian dan IPTEKS, memiliki penguasaan konsep, mampu menyelesaikan masalah prosedural, mampu mengambil keputusan dan bertanggungjawab. Merujuk pada deskripsi level 6 KKNI, maka salah satu capaian pembelajaran mata kuliah (CPMK) Instrumentasi sebagai mata kuliah wajib prodi adalah mahasiswa mampu menjelaskan penggunaan konsep instrumentasi pada penerapan teknologi instrumentasi (memiliki penguasaan konsep). Pada pembelajaran mata kuliah instrumentasi belum terdapat media pembelajaran yang mendukung CPMK tersebut.

Pengembangan media merupakan salah satu upaya untuk membantu mahasiswa mampu menjelaskan penggunaan konsep instrumentasi pada penerapan teknologi instrumentasi. Penggunaan photodioda sebagai sensor untuk mengukur denyut jantung saat ini banyak digunakan oleh para peneliti. Hal tersebut dapat dilihat dari beberapa peneliti lintas negara yang melakukan penelitian terkait pengembangan perangkat pengukur denyut jantung yang menggunakan sensor photodioda (Comert, Istanbullu, \& Turhal, 2014; Verma, \& Bhasin, 2014; Babiker, Adbel-Khair, \& Elbasheer, 2011; dan Wahyu dkk, 2014). Dari berbagai penelitian tersebut, diketahui adanya perbedaan pengkondisi sinyal yang digunakan setelah rangkaian sensor.

Selain tren penggunaan photodida sebagai sensor denyut jantung, hal penting pemilihan perangkat pengukur denyut jantung adalah kebutuhan akan perangkat pengukur denyut jantung yang mudah digunakan dan murah. Penyakit tidak menular (PTM) 
menjadi penyebab utama kematian secara global. Proporsi penyebab kematian PTM pada orang-orang berusia kurang dari 70 tahun, penyakit cardiovaskular merupakan penyebab terbesar (Pusat Data dan Informasi Kementerian Kesehatan RI, 2012:1). Jantung yang tidak normal bisa dilihat dari jumlah denyut jantung yang tidak sesuai dengan kisaran jumlah denyut jantung normal. Denyut jantung adalah jumlah detak jantung per satuan waktu dan biasanya dinyatakan dalam denyut per menit atau beats per minute (bpm). Pada orang dewasa, jantung yang normal berdetak sekitar 60 sampai 90 kali per menit (Darwis dkk, 2008:18). Frekuensi denyut jantung normal orang dewasa dalam hal ini merupakan jumlah denyut jantung yang terjadi dalam satu detik. Oleh karena itu frekuensi denyut jantung normal orang dewasa sekitar $1 \mathrm{~Hz}$ sampai dengan $1,67 \mathrm{~Hz}$ (jumlah getaran dibagi dengan jumlah detik waktu).

Deteksi dini penyakit jantung dapat dilakukan dengan melakukan pengecekkan frekuensi denyut jantung secara teratur. Beberapa cara dapat dilakukan untuk mendeteksi frekeunsi denyut jantung. Perangkat pengukur denyut jantung diantaranya adalah Electrocardiograph (ECG) dan pulse fingertip oximeter. Penggunaan ECG kurang fleksibel penggunaannya karena ukuran yang relatif besar serta memerlukan instalasi dan teknis pengoperasian tertentu yang cenderung rumit, sehingga terbatas oleh tenaga medis. Selain itu ECG relatif mahal. Alternatif lainnya menggunakan ECG mobile yang ada di smarthpone berbasis android. Namun demikian dr. Sinatra (tt) menyatakan bahwa terdapat beberapa permasalahan ketika menggunakan ECG mobile pada smartphone, diantaranya mengganggu variabilitas detak jantung, adanya waktu delay saat pentransmisian data ke smartphone dan terkait efek frekuensi wireless pada tubuh manusia. Dilain pihak pulse fingertip oximeter relatif mahal meskipun penggunaannya mudah. Diperlukan perangkat pengukur denyut jantung yang mudah penggunaannya dan murah. Keterbatasan penggunaan dan faktor biaya menjadi permasalahan pada perangkat pengukur denyut jantung. Penggunaan photodioda sebagai sensor pada perangkat pengukur denyut jantung dinilai mampu menjadi solusi hal tersebut.

Beberapa riset menunjukkan bahwa terdapat sensor lain yang berbeda dengan sensor pada ECG yang dapat dijadikan alternatif sensor pengukur denyut nadi, yaitu sensor pulse oximetry. Sebagai tambahan, Valencell (2015) menyatakan bahwa perangkat yang memantau denyut jantung (termasuk oximetry) menggunakan metode photoplethysmography (PPG). PPG merupakan teknik penyinaran cahaya pada kulit dan mengukur jumlah cahaya yang tersebar melalui aliran darah yang berubah secara dinamis dikarenakan perubahan denyut darah (denyut jantung) atau perubahan volume darah (cardiac output). Gambar 1 memperlihatkan teknik PPG.

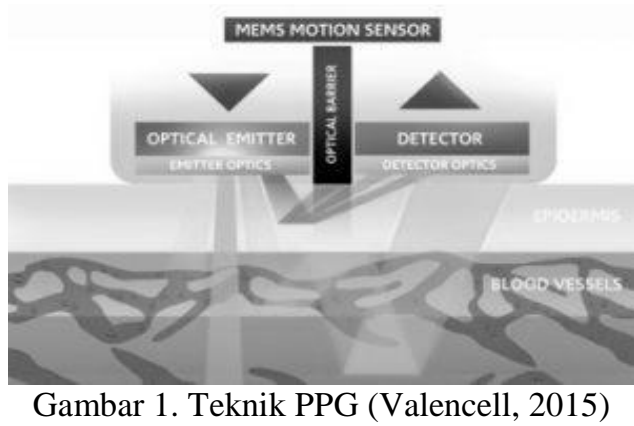

Lebih lanjut lagi Barker dkk (2002) menyatakan bahwa prinsip sensor pulse oxymeter bekerja berdasarkan karakteristik penyerapan cahaya merah dan inframerah (infrared/IR) dari hemoglobin yang mengandung oksigen dan yang tidak (terdeoksigenasi). Hubungan antara penyerapan cahaya oleh hemoglobin seperti tertampil pada Gambar 2.

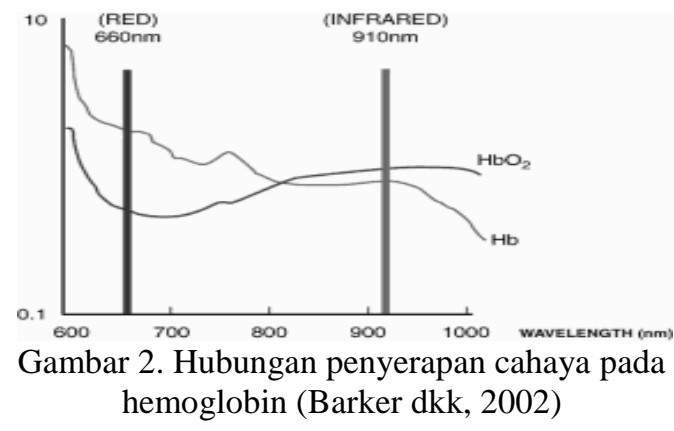


Hemoglobin yang mengandung oksigen menyerap cahaya inframerah dan melewatkan cahaya merah lebih banyak. Sebaliknya pada hemoglobin terdeoksigenasi menyerap cahaya merah dan melewatkan cahaya inframerah lebih banyak. Hal tersebut terjadi dikarenakan adanya perbedaan panjang gelombang diantara cahaya merah (600 -750 nm) dan cahaya inframerah (850-1000 nm). Jagdeo dkk (2012) menyatakan bahwa transmisi cahaya inframerah pada tangan manusia rendah tetapi dapat dihitung dan lebih besar dari transmisi cahaya merah. Sehingga pada media ini dipilih infrared sebagai transmitter cahaya. Sensor oximetry pada prinsipnya menggunakan pancaran cahaya led merah dan infrared dan ditangkap oleh photodetector. Terdapat dua metode dalam mengukur denyut jantung menggunakan sensor tersebut, yaitu metode pancaran (transmission) dan pantulan (reflection) seperti terlihat pada Gambar 3.

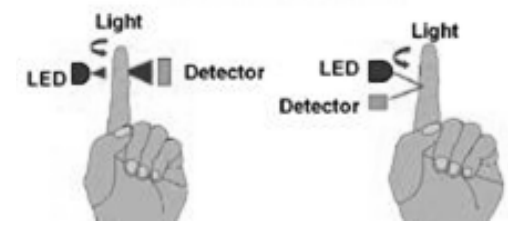

Gambar 3. Metode Transmission (kiri) dan Reflectance (kanan) (Editors, 2007)

Pada metode transmisi, transmitter dan receiver cahaya diposisikan berlawanan dengan jari berada diantara keduanya. Berbeda dengan metode transmisi, pada metode refleksi transmitter dan receiver cahaya berada berdekatan dengan jari berada diatas keduanya. Pada penelitian ini dipilih metode refleksi dengan mempertimbangkan kemudahan pemasangan komponen. Penggunaan metode tersebut hanya pada area- area tertentu seperti jari dan telinga (Barker dkk, 2002; dan Editors, 2007).

Selanjutnya yang perlu menjadi perhatian adalah adanya perbedaan penyerapan cahaya yang terjadi pada jari seperti pada Gambar 4. Variasi penyerapan cahaya pada jari dipengaruhi dari beberapa komponen, yaitu gerakan dan perfusi darah, sedangkan penyerapan cahaya secara konstan terjadi pada kulit, jaringan, darah vena, dan darah arteri.

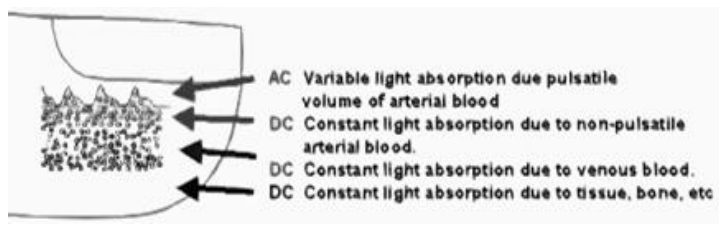

Gambar 4. Penyerapan cahaya karena beberapa komponen di jari (Barker dkk, 2002)

Sinyal biometrik dari PPG yang berkualitas tinggi seperti pada Gambar 5 mendasari pengukuran frekuensi pernafasan, $\mathrm{VO}_{2}$ max, kandungan oksigen dalam darah, variabilitas denyut jantung,tekanan darah dan efisiensi jantung. Meskipun demikian optical noise, warna kulit, croossover problem (gerak dan aktivitas tubuh), lokasi sensor dan perfusi rendah, sehingga dibutuhkan optomekanik dan algoritma ekstraksi sinyal yang bagus. Penggunaan optical heart rate monitoring (OHRM) dengan teknik PPG saat ini berinovasi menjadi perangkat yang mendukung lifestyle, in-session dan pemantauan kesehatan (Valencell, 2015). Dalam penelitian ini teknik PPG terbatas pada membelajarkan mahasiswa mengenai konsep variabel besaran, sensor dan pengkondisi sinyal. Diharapkan dengan penguasaan konsep tersebut, mahasiswa mampu berkontribusi dalam memberikan inovasi OHRM.

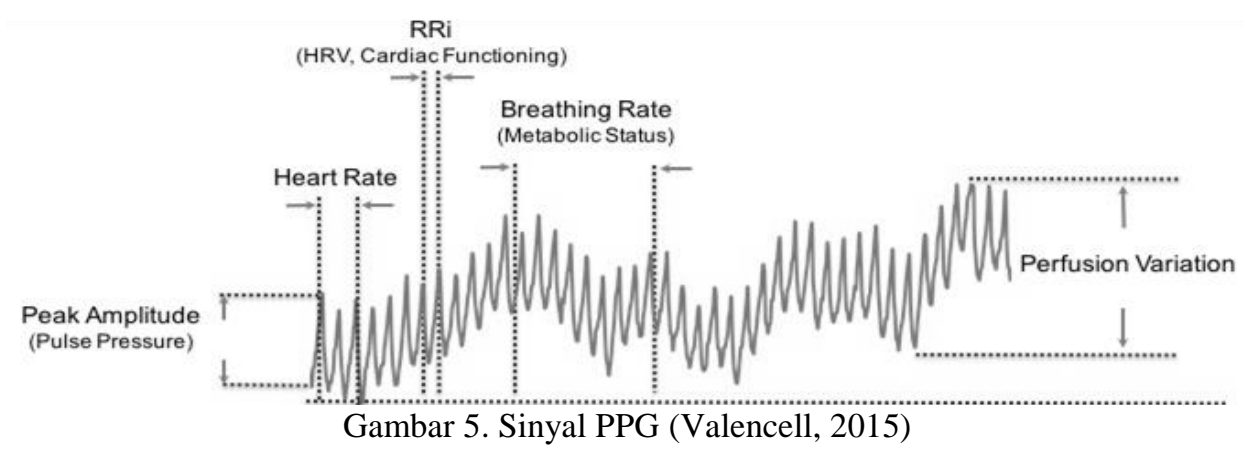


Berdasar pada beberapa penelitian sebelumnya, dalam penelitian ini, photodioda digunakan untuk mengukur aliran darah di ujung jari (fingertip), dimana Infrared (IR) sebagai transmitter dan photodioda sebagai receiver. Adanya penggunaan IR dan photodioda sebagai sensor aliran darah denyut jantung di ujung jari menambah khasanah keilmuan di bidang instrumentasi elektronika. Berdasarkan prinsip-prinsip pembelajaran pendidikan vokasional menurut Prosser (Wardiman, 1998:38), menyatakan bahwa pembelajaran vokasional harus memperhatikan permintaan pasar dalam hal ini penggunaan teknologi yang efektif dan efisien. Dengan demikian khasanah yang mengandung unsur inovasi dan penyiapan lulusan yang kompeten, maka perlu difasilitasi dosen dalam pengajaran di kelas. Tujuan diadakannya penelitian ini adalah diperolehnya trainer pengkondisi sinyal yang dapat menunjukkan adanya penguatan sinyal tegangan terhadap input sinyal tegangan dari sensor IR dan photodioda saat mendeteksi aliran darah (denyut jantung) pada ujung jari.

Pembelajaran merupakan usaha sadar dari pendidik untuk membelajarkan peserta didiknya dengan berinteraksi dengan sumber belajar lain dalam rangka mencapai tujuan yang diharapkan. Media pembelajaran adalah sesuatu yang digunakan untuk menyampaikan informasi pembelajaran agar dapat merangsang pikiran dan perhatian peserta didik (Yusuf, 2009: 458; Arief dkk, 2009:7; dan Azhar, 2007: 6-7). Terkait pemilihan media berbentuk hardware dipilih dikarenakan memprioritaskan capaian tujuan pembelajaran (Yusuf, 2009: 461). Azhar (2007: 26-27) menyatakan bahwa salah satu manfaat penggunaan media dalam proses belajar mengajar yaitu memperjelas penyajian informasi sehingga dapat memperlancar dan meningkatkan proses dan hasil belajar. Manfaat tersebut memliki kesesuaian dengan tujuan pembelajaran mata kuliah Instrumentasi. Tujuan tersebut adalah mampu menjelaskan penggunaan konsep instrumentasi pada penerapan teknologi instrumentasi khususnya mengenai konsep variabel besaran, sensor, dan pengkondisi sinyal. Menurut Azhar (2007: 75) kriteria yang diperhatikan adalah sesuai dengan tujuan; tepat untuk mendukung isi pelajaran bersifat fakta, konsep, prinsip; praktis, luwes dan bertahan; guru terampil menggunakannya; pengelompokkan sasaran; dan mutu teknis. Kriteria tersebut dijadikan dasar dalam melakukan evaluasi media. Evaluasi dilakukan dengan memperhatikan aspek materi, teknis dan tampilan.

\section{METODE}

Metode penelitian ini menggunakan model pengembangan yang terdiri dari analisis kebutuhan, desain pengembangan, implementasi dan evaluasi. Langkah-langkah pengembangan media ditunjukkan pada Tabel 1 .

Tabel 1. Capaian tahapan pengembangan media

\begin{tabular}{ll}
\hline Tahapan & Capaian \\
\hline Analisis & - Rincian tugas peserta didik \\
kebutuhan & - Materi yang diakomodasi media \\
& - Tujuan media \\
& - Jenis media, kebutuhan umum, \\
& kelebihan, keterbatasan dan \\
& pengemasan media \\
& - Manfaat pengembangan media \\
Desain & - Isi media (blok diagram dan titik \\
pengem- & pengukuran) \\
bangan & - Skema dan layout rangkaian \\
& - Desain kemasan perangkat \\
Implemen- & - Layout jobsheet \\
tasi & - Packaging \\
Evaluasi & - Uji unjuk kerja perangkat \\
& - Uji penggunaan \\
\hline
\end{tabular}

Analisis kebutuhan dilakukan dengan melakukan beberapa analisis yang terdiri dari: (1) task analysis untuk mendapatkan gambaran awal mengenai rincian tugas yang akan diberikan kepada peserta didik; (2) criticalinsident analysis untuk menganalisis materi yang diakomodasi media; (3) objective analysis untuk menganalisis tujuan media; (4) media analysis untuk membuat kesimpulan awal mengenai jenis media yang paling tepat digunakan, kebutuhan umum, kelebihan, 
keterbatasan serta pengemasan media; dan (5) benefit analysis untuk menganalisa manfaat/keuntungan yang dapat diperoleh dengan adanya dukungan media yang dikembangkan. Analisis tersebut merujuk pada Front End Analysis menurut Lee \& Owens (2004: 15), dimana analisis disesuaikan dengan kebutuhan pengembangan media. Analisis ini dilakukan dengan melakukan wawancara dengan dosen pengampu. Setelah analisis dilakukan maka diperoleh bahan untuk melakukan desain blok diagram, titik pengukuran, skema dan layout rangkaian serta kemasan perangkat. Desain dilanjutkan dengan implementasi skema pada PCB dan packaging perangkat. Tahapan terakhir adalah evaluasi yang terdiri dari: (1) uji unjuk kerja perangkat berdasarkan indikator keberhasilan dan penilaian ahli mengenai materi (kesesuaian, kelengkapan dan memberikan kesempatan belajar), teknis (fleksibel, keamanan dan kemanfaatan) dan tampilan (bentuk, keserasian, keterbacaan dan kerapian); dan (2) uji penggunaan terbatas pada mahasiswa mengenai kelayakan dan kemampuan media untuk membantu mahasiswa menguasai konsep instrumentasi dari variabel besaran, sensor dan pengkondisi sinyal menggunakan tes lisan dengan menjelaskan alur berfikir konsep variabel besaran, sensor dan pengkondisi sinyal mengenai pengukur denyut nadi pada media. Kelayakan media dinilai mahasiswa menggunakan angket. Teknik analisis deskriptif digunakan untuk menentukan kelayakan media dalam fungsinya dengan melakukan konversi skor rerata ke dalam tingkatan kelayakan. Kriteria sangat layak apabila skor rerata 3,25 s.d. 4; layak apabila skor rerata 2,5 s.d. 3,25; kurang layak apabila skor rerata 1,75 s.d. 2,5 ; dan sangat kurang layak apabila skor rerata 1 s.d. 1,75.

\section{HASIL}

Hasil analisis kebutuhan secara umum menunjukkan bahwa media yang dibuat tidak berbasis mikrokontroler agar mahasiswa tidak memiliki overlap materi. Meskipun demikian, output disesuaikan dengan kebutuhan pemrosesan di mikrokontroler. Hal tersebut dikarenakan beberapa mata kuliah menerapkan pembelajaran berbasis proyek dan semua proyek yang ditugaskan berbasis mikrokontroler. Sebagai tambahan, rangkaian dibangun dari rangkaian yang sebenarnya. Paparan hasil analisis kebutuhan ditunjukkan pada Tabel 2.

Tabel 2. Hasil analisis kebutuhan

\begin{tabular}{ll}
\hline \multicolumn{1}{c}{ Indikator capaian } & \multicolumn{1}{c}{ Hasil } \\
\hline Rincian tugas peserta didik & - Pengukuran tegangan dan bentuk sinyal pada titik-titik pengukuran \\
Materi yang diakomodasi media & - Konsep variabel besaran, sensor, pengkondisi sinyal dan output \\
Tujuan media & - Menjelaskan penggunaan konsep instrumentasi pada penerapan teknologi \\
& instrumentasi (penggunaan sensor photodioda untuk mengukur denyut \\
& jantung), khususnya konsep variabel besaran, sensor dan pengkondisi sinyal \\
Jenis media yang paling tepat & - Jenis media berbentuk objek hardware disertai jobsheet praktik \\
digunakan, kebutuhan umum, & - Kebutuhan umum pengembangan: blok sensor, blok pengkondisi sinyal \\
kelebihan, keterbatasan serta & (band pass filter, penguat non inverting, dan comparator) dan output \\
pengemasan media (tampilan, & - Kelebihan media ini diantaranya: (1) dibuat terstruktur dimulai blok input, \\
bentuk, ukuran, bahan) & proses dan output; (2) dibuat dari rangkaian yang sebenarnya dan sesuai \\
& dengan skema yang tertampil; dan (3) titik-titik pengukuran disusun \\
& berurutan dan besar \\
& - Keterbatasan media ini diantaranya: (1) tidak dikonfigurasikan ke \\
& mikrokontroler, hal tersebut berdasarkan analisis mengenai fokus pada \\
& instrumentasi analog; (2) metode yang dipakai hanya satu (refleksi); (3) \\
& tidakdapat memodifikasi pengkondisi sinyal; dan (4) sinyal output belum \\
& berkualitas bagus untuk dapat menampilkan semua pengukuran biometrik, \\
& sehingga terbatas pada representasi denyut jantung \\
& Media dikemas dalam bentuk boks dengan ukuran menyesuaikan \\
& keterbacaan skema dan penempatan titik-titik pengukuran, bokd media dari \\
& bahan acrylic warna putih.
\end{tabular}




\begin{tabular}{cc}
\hline Indikator capaian & \multicolumn{1}{c}{ Hasil } \\
\hline Manfaat pengembangan media & $\begin{array}{l}\text { Diharapkan media ini dapat bermanfaat untuk memberikan pemahaman } \\
\text { konsep instrumentasi terkait variabel besaran, sensor dan pengkondisi } \\
\text { sinyal pada penerapan photodioda sebagai sensor denyut jantung }\end{array}$ \\
\hline
\end{tabular}

Jenis media berupa media objek hardware yaitu berupa rangkaian yang dikemas dalam boks perangkat dan didukung jobsheet. Jobsheet praktik disusun untuk memandu mahasiswa mengerjakan praktik (tugas) dan berisi materi mengenai konsep variabel besaran, sensor, pengkondisi sinyal dan output. Keterbatasan media terkait tidak dikonfigurasikan ke mikrokontroler adalah agar tidak overlap dengan materi mikrokontroler dan memfokuskan mahasiswa kepada materi instrumentasi dari variabel proses, sensor hingga pengkondisi sinyal. Sehingga output diumpankan pada led yang mengindikasikan terdapat/tidak terdapatnya denyut jantung, meskipun sebenarnya output sudah dapat diproses dengan mikrokontroler. Adanya keterbatasan-keterbatasan media diharapkan tetap dapat mencapai capaian pembelajaran yang diharapkan yaitu mahasiswa mampu menjelaskan konsep instrumentasi pada penerapan teknologi instrumentasi (penggunaan sensor photodioda untuk mengukur denyut jantung), khususnya konsep variabel besaran, sensor dan pengkondisi sinyal. Dengan kesederhanaan rangkaian diharapkan konsep instrumentasi dapat diterima dengan baik oleh mahasiswa dikarenakan kelebihan media berupa pembuatan yang terstruktur dimulai blok input, proses dan output mampu mengkonstruksi pemahaman dengan baik.

Blok diagram rangkaian seperti pada Gambar 6, terdiri dari: (1) blok rangkaian sensor yang terdiri dari rangkaian IR dan photodioda; (2) blok pengkondisi sinyal yang terdiri dari penguat non inverting, band pass filter, dan comparator; dan (3) blok output berupa led. Sehingga didapatkan output tegangan yang telah dikuatkan dan siap diproses pada blok output. Dari blok diagram tersebut tiik pengukuran yang diperlukan adalah: (1) titik pengukuran output sensor sebagai masukan pada pengkondisi sinyal; (2) titik pengukuran output rangkaian penguat non inverting; (3) titik pengukuran output rangkaian band pass filter dan (4) titik pengukuran output rangkaian comparator. Dengan demikian dapat di breakdown kebutuhan komponen pada Tabel 3.

Tabel 3. Kebutuhan komponen rangkaian pengkondisi sinyal

\begin{tabular}{lll}
\hline No. & \multicolumn{1}{c}{ Blok } & \multicolumn{1}{c}{ Komponen } \\
\hline 1 & Sensor & $\begin{array}{l}\text { Photodioda, IR, R } \\
\text { (470R dan 1K) }\end{array}$ \\
2 & Penguat & $\begin{array}{l}\text { LM356, R (68K; } \\
680 \mathrm{~K} ;),\end{array}$ \\
& & C(1uF,100nF), \\
3 & Filter & R(68k,6.8k) \\
& & LM2903, Trimpot \\
4 & Comparator & 10k, R10k \\
& & Acrylic Susu \\
5 & Boks & 3mm,2mm. \\
& perangkat
\end{tabular}

Agar tujuan media tercapai, terdapat alur berfikir yang ditanamkan melalui pembelajaran. Alur berfikir tersebut adalah konsep how, what dan why. Dimana alur berfikir dimulai dari mempertanyakan indikator variabel besaran, sensor sampai dengan pengkondisi sinyal secara berurutan. Alur berfikir tersebut seperti disajikan pada Tabel 4.

Tabel 4. Alur berfikir konsep variabel besaran, sensor dan pengkondisi sinyal

\begin{tabular}{lll}
\hline No. & \multicolumn{1}{c}{ Indikator } & \multicolumn{1}{c}{ Hasil analisis } \\
\hline 1 & Variabel besaran & Darah pada ujung jari: memiliki variasi penyerapan cahaya karena \\
& Bagaimana karakteristik variabel & kadar oksigen dalam hemoglobin sebagai akibat dari perubahan \\
& besaran? (how) & denyut dan volume darah dari jantung. Memiliki faktor \\
& & pengganggu diantaranya: warna kulit, jaringan, pembuluh darah \\
& & vena, pembuluh darah arteri, optical noise, croossover problem \\
& (gerak dan aktivitas tubuh), lokasi sensor dan perfusi rendah. \\
\hline
\end{tabular}




\begin{tabular}{|c|c|c|}
\hline No. & Indikator & Hasil analisis \\
\hline \multirow[t]{3}{*}{2} & $\begin{array}{l}\text { Sensor } \\
\text { Bagaimana metode sensor yang bisa } \\
\text { digunakan untuk mendeteksi variasi } \\
\text { besaran? (how) }\end{array}$ & $\begin{array}{l}\text { Sensor yang dibutuhkan adalah sensor yang mendeteksi cahaya } \\
\text { dengan metode photoplethysmography (PPG). Metode tersebut } \\
\text { terdiri dua teknik yaitu transmisi dan refleksi. Metode refleksi } \\
\text { dipilih dikarenakan faktor kemudahan pemasangan dalam media. }\end{array}$ \\
\hline & $\begin{array}{l}\text { Apa saja sensor yang dapat } \\
\text { mengukur variabel besaran? (what) }\end{array}$ & $\begin{array}{l}\text { Sensor-sensor tersebut diantaranya adalah: photodioda, } \\
\text { phototransistor dan LDR. Dalam media ini dipilih photodioda } \\
\text { (Comert, Istanbullu, \& Turhal, 2014; Verma, \& Bhasin, 2014; } \\
\text { Babiker, Adbel-Khair, \& Elbasheer, 2011; dan Wahyu dkk, 2014) } \\
\text { (why). Sensor tersebut membutuhkan transmitter cahaya. }\end{array}$ \\
\hline & $\begin{array}{l}\text { Apa saja komponen yang dapat } \\
\text { digunakan sebagai transmitter } \\
\text { cahaya? (what) }\end{array}$ & $\begin{array}{l}\text { Transmitter cahaya diantaranya LED (merah, kuning, biru, hijau, } \\
\text { ungu dan sebagainya), laser diode, dan infrared. Infrared dipilih } \\
\text { karena transmisi cahayanya lebih besar dari cahaya merah (why). }\end{array}$ \\
\hline \multirow[t]{3}{*}{3} & $\begin{array}{l}\text { Pengkondisi sinyal } \\
\text { Apa output yang diharapkan dari } \\
\text { rangkaian pada media? (what) }\end{array}$ & $\begin{array}{l}\text { Output LED dipilih berdasarkan penampilan indikator yang } \\
\text { sederhana dan cukup merepresentasikan denyut jantung dari } \\
\text { frekuensi nyala/mati LED. Selain itu output juga dapat } \\
\text { dihubungkan sebagai input mikrokontroler untuk mengakomodasi } \\
\text { minat bereksplorasi mahasiswa. (why) }\end{array}$ \\
\hline & $\begin{array}{l}\text { Apa saja kebutuhan agar output } \\
\text { sensor dapat dikondisikan sesuai }\end{array}$ & $\begin{array}{l}\text { Untuk mengakomodasi output akhir berupa kondisi nyala/mati } \\
\text { LED dan input mikrokontroller, maka dibutuhkan rangkaian yang: }\end{array}$ \\
\hline & $\begin{array}{l}\text { harapan? (what) } \\
\text { Rangkaian apa yang digunakan? } \\
\text { (what) }\end{array}$ & $\begin{array}{l}\text { a. dapat melewatkan sinyal tertentu akibat salah satu karakteristik } \\
\text { metode PPG berupa adanya optical noise dan frekuensi denyut } \\
\text { jantung yang rendah (1 Hz sampai dengan } 1,67 \mathrm{~Hz} \text { ), sehingga } \\
\text { diperlukan rangkaian low pass filter (LPF). Namun menimbang } \\
\text { bahwa rangkaian penguat sinyal tidak boleh ada sinyal DC yang } \\
\text { dilewatkan, sehingga rangkaian LPF tidak bisa diterapkan } \\
\text { dibagian awal rangkaian, akan tetapi membutuhkan rangkaian } \\
\text { high pass filter (HPF). Dimana kapasitor pada HPF berfungsi } \\
\text { menahan tegangan DC. Oleh karena itu rangkaian filter yang } \\
\text { digunakan adalah rangkaian band pass filter (BPF).(why); } \\
\text { b. memerlukan penguatan dikarenakan output sensor dalam orde } \\
\text { mV, sedangkan kebutuhan sebagai input LED adalah } 2 \mathrm{~V}-3 \mathrm{~V} \text {, } \\
\text { sehingga dibutuhkan sekitar } 10 \text { sampai dengan } 100 \text { kali } \\
\text { penguatan. Dari kebutuhan tersebut, maka dibutuhkan rangkaian } \\
\text { penguat non inverting agar polaritas output yang sama dengan } \\
\text { polaritas input, dan memiliki fasa yang sama. (why); } \\
\text { c. hanya memiliki dua logika yaitu logika high dan low agar nilai } \\
\text { output bisa diteruskan ke mikrokontroler, sehingga dibutuhkan } \\
\text { Rangkaian komparator dibutuhkan tepat sebelum rangkaian } \\
\text { output LED dan atau output ke mikrokontroler. (why). }\end{array}$ \\
\hline
\end{tabular}

Alur berfikir seperti pada Tabel 4 akan memudahkan mahasiswa untuk memahami konsep instrumentasi dari variabel besaran, sensor dan pengkondisi sinyal. Alur berfikir tersebut digunakan untuk penyusunan blok diagram dari perangkat. Blok diagram perangkat media secara umum yang terdiri dari tiga blok, yaitu blok sensor, blok pengkondisi sinyal dan blok output. Dalam blok pengkondisi sinyal terdapat rangkaian filter, penguat dan komparator. Gambar 6 menunjukkan diagram blok dari rangkaian pada perangkat media ini.

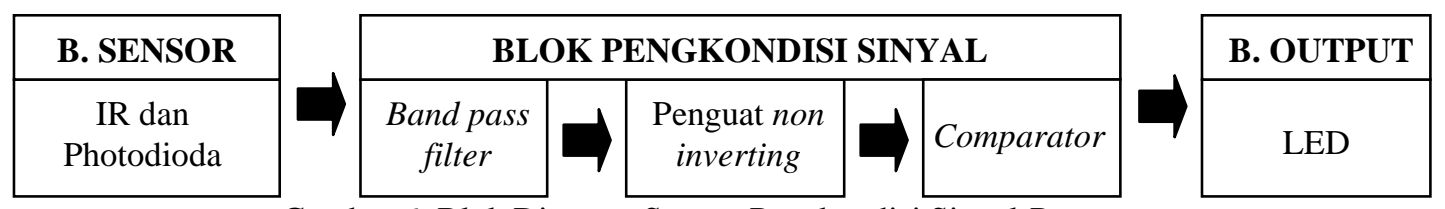

Gambar 6. Blok Diagram Sensor-Pengkondisi Sinyal-Pemroses 
Secara umum cara kerja rangkaian adalah variabel besaran berupa aliran darah di ujung jari di konversi menjadi besaran listrik oleh blok sensor yaitu infrared sebagai transmitter dan photodioda sebagai receiver cahaya. Output dari sensor selanjutnya melalui proses pengkondisian sinyal oleh filter, penguat dan komparator sampai dengan didapatkan output yang sesuai untuk mengkondisikan led. Digunakan rangkaian penguat dikarenakan output sensor berada pada orde $\mathrm{mV}$, sedangkan diharapkan output sensor dapat digunakan untuk menyalakan led. Standard LED (red) memerlukan tegangan $2 \mathrm{~V}$ $-3 \mathrm{~V}$ (Vishay, 2015). Filter yang digunakan

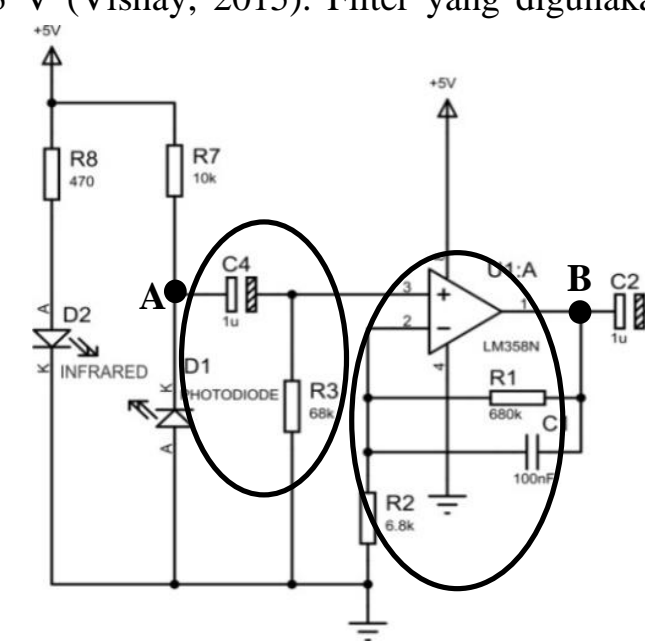

Gambar 7. Skema rangkaian dan titik-titik pengukuran adalah band pass filter. Penggunaan filter tersebut merujuk pada Nguyen \& Horjus (2011) yang menggunakan band pass filter (BPF). BPF digunakan untuk menghilangkan interferensi yang disebabkan oleh cahaya dan distorsi, serta membatasi frekuensi yang sesuai dengan frekuensi denyut jantung. Filter dirancang dengan frekuensi cut off sebesar 2Hz. Komparator digunakan untuk mengkomparasi nilai tegangan yang masuk antara tegangan referensi, sehingga keluaran komparator dapat memberikan tegangan yang sesuai baik untuk led maupun untuk input mikrokontroler.
Setelah mendesain skema, tahap berikutnya adalah menentukan titik-titik pengukurn. Untuk mendukung pembelajaran, maka terdapa lima titik pengukuran, yaitu (1) Titik A merupakan output sensor photodioda; (2) titik B merupakan output BPF yang terdiri dari rangkaian HPF dan LPF; (3) titik C merupakan output rangkaian penguat non inverting; (4) titik D merupakan pengukuran nilai RV1 sebagai tegangan referensi untuk mengatur output komparator; dan (5) titik $\mathrm{E}$ merupakan output komparator. Selain lima titik pengukuran, pada media terdapat titik ground yang dibedakan dengan warna. Dimana lima titik pengukuran berwarna merah, sedangkan titik ground berwarna hitam.
Tahapan desain terdiri dari pembuatan skema dan layout rangkaian, pembuatan desain packaging berbentuk kotak dari bahan acrylic, dan sistematika jobsheet. Jobsheet disusun untuk mendukung pelaksanaan praktik menggunakan media. Secara umum sistematika jobsheet terdiri dari: identitas jobsheet, capaian pembelajaran praktik, kajian teori, alat dan bahan, langkah kerja, data praktikum dan analisis, bahan diskusi, simpulan dan daftar rujukan. Tahapan implementasi dilakukan dengan mengimplementasikan skema pada PCB dan dilanjutkan dengan packaging. Gambar 8 menunjukkan trainer dari media yang dikembangkan. 


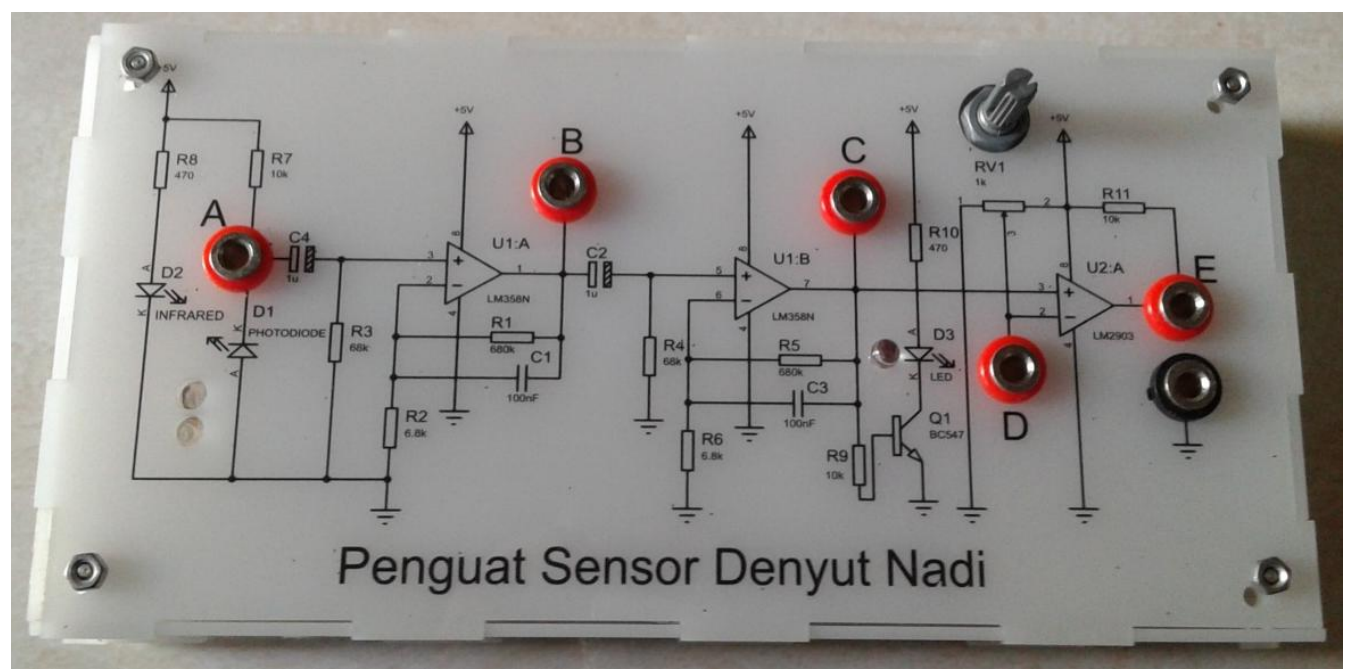

Gambar 8. Trainer denyut jantung

Setelah diimplementasikan, media dievaluasi tahap awal dengan melakukan uji unjuk kerja. Uji unjuk kerja ini disusun berdasarkan indikator-indikator yang disusun oleh peneliti untuk menghasilkan media yang sesuai dengan tujuan. Data hasil unjuk kerja ditampilkan pada Tabel 5. Secara umum hasil unjuk kerja sesuai dengan harapan, dimana semua unjuk kerja sesuai dengan kajian dan indikator ketercapaian/ hasil yang diharapkan.

Tabel 5. Data hasil unjuk kerja

\begin{tabular}{|c|c|c|c|c|}
\hline Test case & Skenario pengujian & Hasil yang diharapkan & $\begin{array}{c}\text { Hasil } \\
\text { pengujian }\end{array}$ & $\begin{array}{l}\text { Sim- } \\
\text { pulan }\end{array}$ \\
\hline $\begin{array}{l}01 \text { pemberian input } \\
\text { tegangan }\end{array}$ & $\begin{array}{l}\text { Menghubungkan } \\
\text { dengan sumber } \\
\text { tegangan }\end{array}$ & Terukur tegangan input pada jalur VCC & $\begin{array}{l}\text { Sesuai } \\
\text { harapan }\end{array}$ & Valid \\
\hline $\begin{array}{l}02 \text { pengukuran titik } \\
\text { pengukuran } \mathrm{A}\end{array}$ & $\begin{array}{l}\text { - Meletakan jari } \\
\text { tangan diatas }\end{array}$ & Sinyal masih lemah dan ada noise & $\begin{array}{l}\text { Sesuai } \\
\text { harapan }\end{array}$ & Valid \\
\hline $\begin{array}{l}03 \text { pengukuran titik } \\
\text { pengukuran } \mathrm{B}\end{array}$ & $\begin{array}{l}\text { blok } \\
\text { (Infrared dan } \\
\text { photodioda). }\end{array}$ & $\begin{array}{l}\text { Sudah terlihat bentuk sinyal berbeda } \\
\text { dengan sinyal di titik } \mathrm{A} \text {, dikarenakan } \\
\text { terjadi filter. }\end{array}$ & $\begin{array}{l}\text { Sesuai } \\
\text { harapan }\end{array}$ & Valid \\
\hline $\begin{array}{l}04 \text { pengukuran titik } \\
\text { pengukuran } \mathrm{C}\end{array}$ & $\begin{array}{l}\text { - Menyambungkan } \\
\text { titik pengukuran } \\
\text { A, B, C dan E ke } \\
\text { CRO. } \\
\text { - Menvambungkan }\end{array}$ & $\begin{array}{l}\text { Sudah terlihat bentuk sinyal berbeda } \\
\text { dengan sinyal di titik A dan B, } \\
\text { dikarenakan terjadi penguatan, nilai output } \\
\text { siap untuk men-drive led. }\end{array}$ & $\begin{array}{l}\text { Sesuai } \\
\text { harapan }\end{array}$ & Valid \\
\hline $\begin{array}{l}05 \text { pengukuran titik } \\
\text { pengukuran } \mathrm{D}\end{array}$ & $\begin{array}{l}\text { titik pengukuran } \\
\text { D ke multimeter. }\end{array}$ & $\begin{array}{l}\text { Nilai tegangan referensi dapat diatur untuk } \\
\text { menghasilkan output komparator sesuai. }\end{array}$ & $\begin{array}{l}\text { Sesuai } \\
\text { harapan }\end{array}$ & Valid \\
\hline $\begin{array}{l}06 \text { pengukuran titik } \\
\text { pengukuran } \mathrm{E}\end{array}$ & & $\begin{array}{l}\text { Sudah terlihat bentuk sinyal berbeda } \\
\text { dengan sinyal di titik A, B dan C, } \\
\text { dikarenakan terjadi sudah ada modifikasi } \\
\text { dari komparator. Nilai output siap } \\
\text { diteruskan ke mikrokontroler. }\end{array}$ & $\begin{array}{l}\text { Sesuai } \\
\text { harapan }\end{array}$ & Valid \\
\hline
\end{tabular}

Sebagai tambahan, Tabel 6 menyajikan informasi hasil pengukuran tegangan pada input, penguat non inverting, blok band pass filter dan comparator. Sinyal dari titik pengukuran A, B, C dan E diperlihatkan pada Gambar 9 sampai dengan Gambar 12.
Tabel 6. Hasil pengukuran tegangan

\begin{tabular}{clc}
\hline No. & \multicolumn{1}{c}{ Blok } & Tegangan \\
\hline 1 & Output sensor & $90.6 \mathrm{mV}$ \\
2 & Output Bandpass filter & $81.4 \mathrm{mV}$ \\
3 & Output Penguat non inverting & $2.44 \mathrm{~V}$ \\
4 & Output Comparator & Tergantung \\
& & supply \\
& & $(0 / 5 \mathrm{~V})$ \\
\hline
\end{tabular}




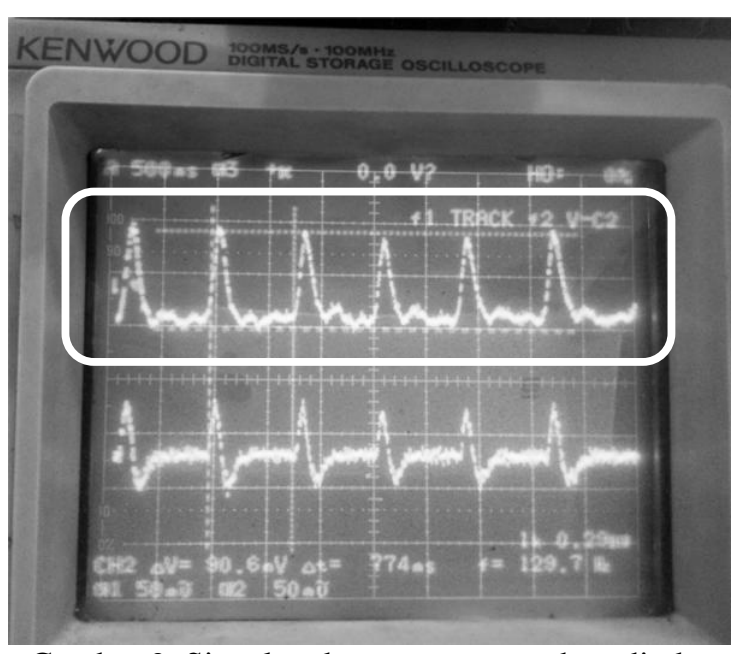

Gambar 9. Sinyal padaoutput sensor photodioda

Tegangan output sensor yang terukur adalah $90,6 \mathrm{mV}$ dan terlihat dari Gambar 10 bahwa sinyal masih memiliki noise dan lemah. Sinyal tersebut belum dapat langsung diteruskan baik pada LED maupun pada mikrokontroler. Oleh karena itu diperlukan pengkondisian sinyal. Gambar 10 menunjukkan sinyal pada titik pengukuran B.

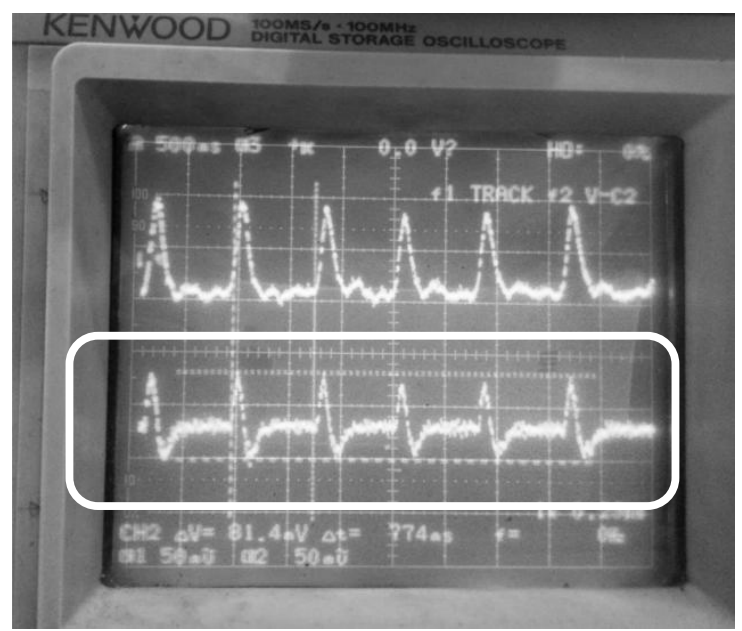

Gambar 10. Sinyal setelah rangkaian band pass pertama

Output dari rangkaian BPF tidak terjadi penguatan, malah justru adanya penurunan menjadi $81,4 \mathrm{mV}$. Hal ini terjadi, karena pada rangkaian band pass pertama impendansinya terpengaruh juga dengan $\mathrm{R} 7$. Pada rangkaian band pass pertama difokuskan pada penentuan batas frekuensi yang dapat dilewatkan. Band pass terdiri dari rangkaian High pass dan Low pass. High pass diletakkan didepan agar bisa melewatkan frekuensi, fungsi High pass juga sebagai penahan tegangan DC agar tidak masuk ke rangkaian. Perhitungan frekuensi cut off pada rangkaian ini adalah sebagai berikut.

Tabel 7. Perhitungan frekuensi pada BPF

\begin{tabular}{|c|c|}
\hline HPF & LPF \\
\hline$f c_{H I G H}$ & $\overline{f c_{\text {LOW }}}$ \\
\hline 1 & 1 \\
\hline $\begin{array}{c}=\overline{2 * \pi * C_{1} * R_{3}} \\
1\end{array}$ & $\begin{array}{r}=\overline{2 * \pi * C_{2} * R_{4}} \\
1\end{array}$ \\
\hline $\begin{array}{l}=\overline{2 * \pi * 1 u F * 68 k} \\
=2.34 \mathrm{~Hz}\end{array}$ & $\begin{array}{l}=\overline{2 * \pi * 100 n F * 680 k} \\
=2.34 \mathrm{~Hz}\end{array}$ \\
\hline ... (perhitungan ke-1) & ... (perhitungan ke-2) \\
\hline
\end{tabular}

Dari hasil perhitungan didapati frekuensi cut off-nya adalah $2.34 \mathrm{~Hz}$. Hasil ini didapat dari pemilihan nilai resistor dan capasitor agar hasil $\mathrm{Fc}$ nya mendekati frekuensi denyut nadi. Penguatan sinyal hasil pengamatan menggunakan bantuan Oscilloscope seperti pada perhitungan ke-3 berikut.

$$
A v=\frac{\text { Vout titik } B}{\text { Vin Titik } A}=\frac{81.4 \mathrm{mV}}{90.6 \mathrm{mV}}=0,8 \text { kali }
$$

Penguatan tersebut didapatkan dari hasil perhitungan yang telah dilakukan sebelumnya. Meskipun demikian, terdapat perbedaan penguatan yang tidak jauh berbeda. Hasil perhitungan seperti berikut.

$$
\begin{aligned}
\frac{V o}{V i} & =\left(1+\frac{R 1}{R 2}\right) \times\left(\frac{R_{3} \| R_{7} C_{4}}{1+R_{3} \| R_{7} C_{4}}\right) \times \frac{1+\left(R_{1} \| R_{2}\right) C_{1}}{1+R_{1} C_{1}} \\
& =\left(1+\frac{680 k}{6.8 k}\right) \times\left(\frac{68 k \| 10 \mathrm{k} .1 u F}{1+68 k \| 10 \mathrm{k} .1 \mathrm{uF}}\right) \times \frac{1+(680 \mathrm{k} \| 6.8 \mathrm{k}) 100 \mathrm{nF}}{1+680 \mathrm{k} .100 \mathrm{nF}} \\
& =\left(\frac{686800}{6.8 k}\right) \times\left(\frac{0.0087}{1.0087}\right) \times \frac{1+(6732.67) 100 \mathrm{nF}}{1+680 \mathrm{k} .100 \mathrm{nF}} \\
& =\left(\frac{686800}{6.8 \mathrm{k}}\right) \times\left(\frac{0.0087}{1.0087}\right) \times \frac{1.00067}{1.068} \\
& =101 \times 0.00864 \times 0.937 \\
A v & =0,82 \text { kali ... (perhitungan ke-4) }
\end{aligned}
$$

Pada hasil perhitungan dan pengamatan nilainya relatif tidak jauh berbeda. Selanjutnya setelah melewati rangkaian band pass, pengukuran dilakukan pada titik $\mathrm{C}$ untuk mengetahui hasil penguatan setelah rangkaian penguat kedua. Gambar 11 menunjukkan sinyal pada titik pengukuran $\mathrm{C}$. 


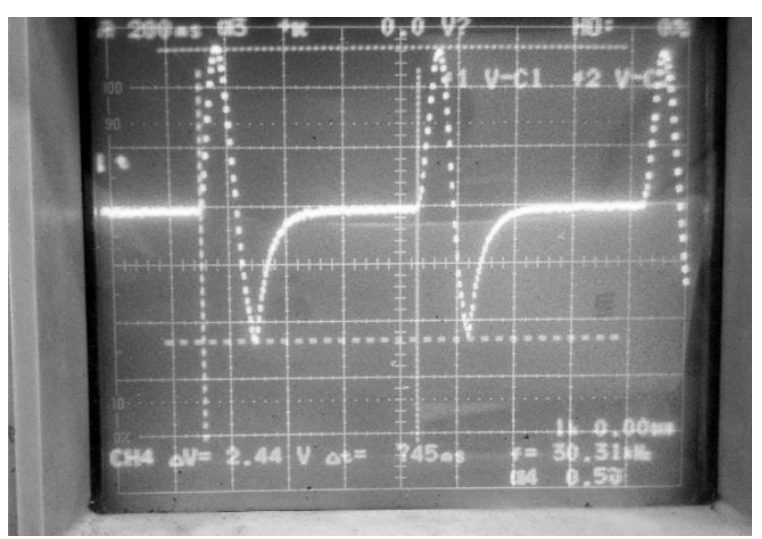

Gambar 11. Hasil gelombang pada titik C setelah rangkaian penguat kedua

Dari hasil pengamatan dapat dilihat bahwa tinggi gelombang adalah $2.44 \mathrm{~V}$, sehingga dapat disimpulkan bahwa output rangkaian penguat kedua telah meningkat ke dalam rentang yang dapat digunakan untuk menghidupkan LED. Sehingga setelah rangkaian penguat kedua, ditambahkan rangkaian LED sebagai penanda atau indikator adanya sinyal denyut jantung. Perhitungan penguatan dari hasil pengamatan pada oscilloscope ditunjukkan pada perhitungan berikut ini.

$$
\begin{gathered}
A v=\frac{\text { Vout titik } D}{\text { Vin Titik } C}=\frac{2.44 \mathrm{~V}}{81.4 \mathrm{mV}}=29,9 \mathrm{kali} \\
\ldots(\text { perhitungan } \mathrm{ke}-5)
\end{gathered}
$$

Penguatan tersebut didapatkan dari hasil perhitungan yang telah dilakukan sebelumnya. Meskipun demikian, terdapat perbedaan penguatan seperti berikut ini.

$$
\begin{aligned}
\frac{V o}{V i} & =\left(1+\frac{R 5}{R 6}\right) \times\left(\frac{R_{4} \cdot C_{2}}{1+R_{4} \cdot C_{2}}\right) \times \frac{1+\left(R_{5} \| R_{6}\right) C_{3}}{1+R_{5} C_{3}} \\
& =\left(1+\frac{680 k}{6.8 k}\right) \times\left(\frac{68 k .1 u F}{1+68 k .1 u F}\right) \times \frac{1+(680 \mathrm{k} \| 6.8 \mathrm{k}) 100 \mathrm{nF}}{1+680 \mathrm{k} .100 \mathrm{nF}} \\
& =\left(\frac{686800}{6.8 k}\right) \times\left(\frac{0.68}{1.68}\right) \times \frac{1+(6732.67) 100 \mathrm{nF}}{1+680 \mathrm{k} .100 \mathrm{nF}} \\
& =\left(\frac{686800}{6.8 k}\right) \times\left(\frac{0.68}{1.68}\right) \times \frac{1.00067}{1.068} \\
& =101 \times 0.404 \times 0.937
\end{aligned}
$$

$A v=38,3$ kali... (perhitungan ke-6)

Dari data perhitungan ke-5 dan ke-6, maka dapat dilihat selisih antara hasil pengamatan dan perhitungan. Hal ini terjadi karena adanya toleransi komponen. Tetapi dilihat dari pencapaian output yang diukur pada titik $\mathrm{C}$ sudah sesuai harapan. Output pada titik $\mathrm{C}$ ini dimasukkan pada rangkaian LED sehingga setiap ada denyut nadi LED menyala.

Kemudian jika mengamati pada rangkaian terakhir, yaitu rangkaian komparator. Rangkaian komparator ini adalah rangkaian terakhir untuk mempertegas gelombang olahan menjadi gelombang kotak (squarewave) yang berlogika 1 dan 0 . Tegangan output rangkaian komparator mengacu pada tegangan referensi yang diatur melalui RV1. Output dari rangkaian komparator berupa squarewave yang siap digunakan pada rangkaian mikrokontroler. Besar output logika 1 (High) mengikuti supply tegangannya, sedangkanlogika 0 (Low) adalah $0 \mathrm{~V}$. Gambar 12 menunjukkan sinyal output pada titik pengukuran $\mathrm{E}$.

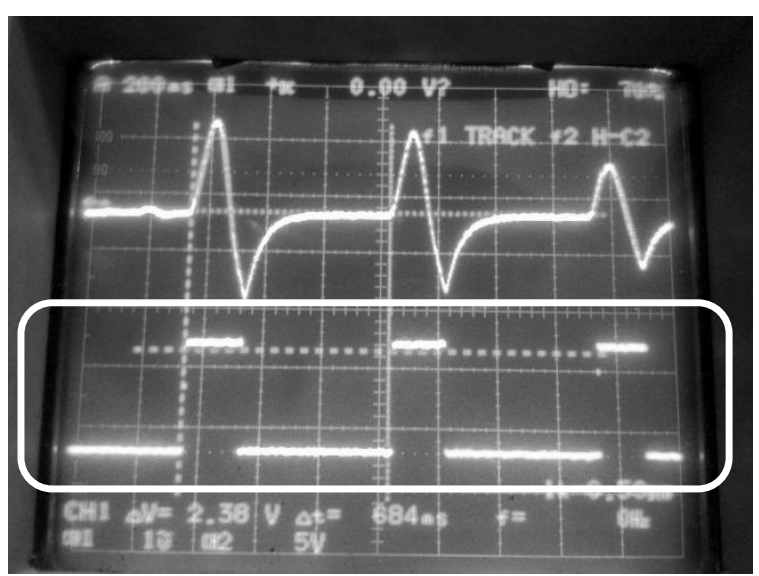

Gambar 12. Hasil gelombang output rangkaian komparator pada titik D

Uji unjuk kerja berikutnya adalah menghitung denyut jantung dengan melakukan pengaturan pada komparator dan menghitung tegangan referensi pada titik pengukuran $\mathrm{D}$. Tabel 8 menunjukkan hasil pengukuran jumlah denyut jantung dengan beberapa kali pengukuran. Pembanding menggunakan pengukuran manual oleh tenaga ahli yang berlatar belakang memiliki wawasan mengenai pengukuran denyut jantung secara manual. 
Tabel 8. Perbandingan hasil pengukuran denyut jantung manual oleh ahli dan pada media

\begin{tabular}{lcccc}
\hline No. & $\begin{array}{c}\text { Jumlah } \\
\text { denyut } \\
\text { jantung }\end{array}$ & $\begin{array}{c}\text { Jumlah } \\
\text { frekuensi } \\
\text { led output }\end{array}$ & Selisih & Error \\
\hline 1 & 83 & 83 & 0 & $0 \%$ \\
2 & 66 & 66 & 0 & $0 \%$ \\
3 & 90 & 90 & 0 & $0 \%$ \\
\hline
\end{tabular}

Catatan: jumlah denyut nadi teraba jari pada area nadi radialis dengan pengambilan jangka waktu yang berbeda.

Setelah uji unjuk kerja, selanjutnya dilakukan penilaian dengan ahli yang menunjukkan bahwa media telah bekerja sesuai dengan yang diharapkan dan terdapat kesesuaian penugasan dan materi yang diberikan pada jobsheet. Simpulan penilaian ahli dari sisi materi adalah: (1) isi materi pada media sesuai dengan tujuan yang akan dicapai; (2) materi yang ada pada jobsheet lengkap dan membantu penguasaan konsep; (3) kegiatan praktikum diuraikan secara jelas dalam jobsheet; dan (4) media memberikan fitur untuk pengembangan materi yang lebih tinggi. Simpulan penilaian ahli dari sisi teknis adalah: (1) penggunaan media cukup fleksibel; (2) media aman dan terdapat prosedur K3 dalam jobsheet; (3) media dapat mempercepat pembelajaran; dan (4) mempermudah dosen menyampaikan materi. Simpulan penilaian ahli dari sisi tampilan adalah: (1) kualitas boks baik; (2) pengaturan tata letak komponen dan titik pengukuran sesuai dengan skema sesungguhnya memudahkan alur berfikir; (3) ukuran media sesuai dengan kebutuhan; (4) skema pada media jelas; dan (5) format, ukuran, warna, teks dan ilustrasi pada jobsheet jelas. Penilaian ahli tersebut dilanjutkan dengan melakukan penilaian kelayakan kepada mahasiswa yang mendapatkan perolehan skor rerata 3,13 sehingga termasuk dalam kategori layak. Selanjutnya evaluasi penggunaan media terhadap mahasiswa menunjukkan bahwa perolehan skor rerata ujian lisan adalah 82 . Dengan demikian penggunaan trainer tersebut memudahkan mahasiswa dalam menjelaskan variabel proses, sensor, pengkondisi sinyal dan output dari media pembelajaran pengukur denyut jantung yang dikembangkan.

\section{SIMPULAN}

Hasil menunjukkan bahwa: (1) media berupa trainer berbentuk kotak yang berisikan titik-titik pengukuran (sensor, pengkondisi sinyal dan output) diatas skema rangkaian sesungguhnya dan jobsheet praktik; dan (2) evaluasi menunjukkan bahwa trainer memiliki unjuk kerja yang sesuai dan mendapat penilaian layak dari mahasiswa. Sebagai tambahan penggunaan trainer tersebut memudahkan mahasiswa dalam memaparkan variabel proses, sensor, pengkondisi sinyal dan output dari media pembelajaran pengukur denyut jantung yang dikembangkan.

\section{DAFTAR RUJUKAN}

Azhar Arsyad. 2007. Media Pembelajaran. Jakarta: PT Raja Grafindo Persada.

Arief Sadiman dkk. 2009. Media Pendidikan: Pengertian, Pengembangan dan Pemanfaatannya. Jakarta: PT RajaGrafindo Persada.

Babiker, S.F., Adbel-Khair, L.E., \& Elbasheer, S.M. 2011. Microcontroler Based Heart Monitor Using Fingertip Sensors. UofKEJ 1, no. 2 hal: 47-51.

Barker, Steven J., Hay, Bill., Miyasaka, Katsuyuki., \& Poets, Christian. 2002. Principles of Pulse Oximetry Technology. Oximetry.org. Diakses dari http://www.oximetry.org/pulseox/princi ples.htm

Comert, B., Istanbullu, A., \& Turhal, U. 2014. Low Cost and Portable Heartbeat Rate Measurement From The Finger. Proceedings The 5th International Symposium on Sustainable Development hal. 197-204.

Darwis dkk. 2008. Pertolongan pertama palang merah remaja tingkat wira. Palang Merah Indonesia Pusat: Jakarta.

Editors. 2007. Reflectance pulse oximetry from SPO medical. Medgadget. Diakses dari http://www.medgadget.com/2007/11/ref lectance_pulse_oximetry_from_spo_me dical.html 
Jagdeo JR, Adams LE, Brody NI, \& Siegel DM. 2012. Transcranial Red and Near Infrared Light Transmission in a Cadaveric Model. PLoS ONE 7(10): e47460.

doi:10.1371/journal.pone.0047460.

Diakses

dari http://journals.plos.org/plosone/article?i $\mathrm{d}=10.1371$ /journal.pone. 0047460

Lee, W. \& Owens, D. (2004). MultimediaBased Instructional Design. San Francisco: Jossey-Bass/Pfeiffer

Nguyen, Wesley., \& Horjus, Ryan. 2011. Heart-Rate Monitoring Control System Using Photoplethysmography (PPG). Senior Project. California Polytechnic State University: San Luis Obispo.

Pusat Data dan Informasi Kementerian Kesehatan RI. 2012. Penyakit Tidak Menular. Buletein Jendela Data dan Informasi Kesehatan. Kementerian Kesehatan RI: Jakarta.

Republik. 2012. Undang-undang Republik Indonesia nomor 12 tahun 2012 tentang pendidikan tinggi. Jakarta

Sinatra. tt. Your smartphone is a protable ecg machine. Dr.Sinatra. Diakses dari http://www.drsinatra.com/yoursmartphone-is-a-portable-ecg-machine/
Valencell, Team. 2015. Optical heart rate monitoring: what you need to know. Valencell. Diakses dari http://valencell.com/blog/2015/10/optica 1-heart-rate-monitoring-what-you-needto-know/

Verma, D., \& Bhasin, M. 2014. Real Time Optical Heart Rate Monitor. International Journal of Computer Science and Information technologies (IJCSIT) 5, no. 6 hal. 7265-7269.

Vishay. 2015. High Efficiency LED in $\emptyset 5 \mathrm{~mm}$ Tinted Diffused Package. Diakses dari www.vishay.com/docs/83219/tlhg640.pd $f$

Wahyu dkk. 2014. FPGA Based Heartbeats Monitor With Fingertip Optical Sensor. International Journal of Computer Science, Engineering and Information Technology (IJCSEIT) 4, no. 5 hal: 19Wardiman Djojonegoro. 1998. Pengembangan sumber daya manusia melalui sekolah menengah kejuruan $(S M K)$. Jakarta: PT Jayakarta Agung Offset.

Yusuf Hadi Miarso. 2009. Menyemai Benih Teknologi Pendidikan. Jakarta: Kencana Prenada Media group atas kerjasama Pustekkom-DIKNAS. 